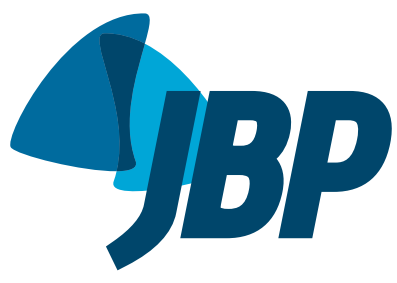

\title{
An initial experience with a digital drainage system during the postoperative period of pediatric thoracic surgery
}

\author{
Altair da Silva Costa Jri,2,3, Thiago Bachichi ${ }^{1}$, Caio Holanda1, \\ Luiz Augusto Lucas Martins De Rizzo ${ }^{4}$
}

1. Disciplina de Cirurgia Torácica, Departamento de Cirurgia, Hospital São Paulo, Escola Paulista de Medicina, Universidade Federal de São Paulo, São Paulo (SP) Brasil.

2. Disciplina de Cirurgia Torácica, Faculdade de Medicina, Fundação ABC Santo André (SP) Brasil.

3. SurgP\&D - Consultoria, Pesquisa e desenvolvimento em Cirurgia, São Paulo (SP) Brasil.

4. Escola Paulista de Medicina, Universidade Federal de São Paulo, São Paulo (SP) Brasil.

Submitted: 21 October 2015

Accepted: 9 March 2016

Study carried out at the Hospital São

Paulo, Escola Paulista de Medicina,

Universidade Federal de São Paulo, São

ABSTRACT

Objective: To report an initial experience with a digital drainage system during the postoperative period of pediatric thoracic surgery. Methods: This was a prospective observational study involving consecutive patients, $\leq 14$ years of age, treated at a pediatric thoracic surgery outpatient clinic, for whom pulmonary resection (lobectomy or segmentectomy via muscle-sparing thoracotomy) was indicated. The parameters evaluated were air leak (as quantified with the digital system), biosafety, duration of drainage, length of hospital stay, and complications. The digital system was used in 11 children (mean age, $5.9 \pm 3.3$ years). The mean length of hospital stay was $4.9 \pm 2.6$ days, the mean duration of drainage was $2.5 \pm 0.7$ days, and the mean drainage volume was $270.4 \pm 166.7 \mathrm{~mL}$. The mean maximum air leak flow was $92.78 \pm 95.83 \mathrm{~mL} / \mathrm{min}$ (range, 18-338 $\mathrm{mL} / \mathrm{min}$ ). Two patients developed postoperative complications (atelectasis and pneumonia, respectively). The use of this digital system facilitated the decision-making process during the postoperative period, reducing the risk of errors in the interpretation and management of air leaks.

Keywords: Drainage; Thoracic surgery; Pediatrics.

Paulo (SP) Brasi.

\section{INTRODUCTION}

Most patients undergoing lung surgery require adequate drainage of the pleural cavity to remove air or fluid and to allow expansion of the remaining lung. It is necessary that the health care team be qualified to manage the drainage system correctly. ${ }^{(1)}$ The measurement or grading of air leaks is still subjective and depends on the level of experience of professionals in quantifying them. Therefore, the interpretation of air leaks is related to observer variability. ${ }^{(1,2)}$ Interobserver disagreement may occur, even between experienced observers. When uncertainty resulting from the use of a traditional system persists, the chest tube may be closed and radiographic assessment may be performed. In such cases, the patient remains in the hospital for at least another day, which results in greater use of resources and time.

In recent years, clinical signs, such as blood pressure, $\mathrm{HR}, \mathrm{SpO}_{2}$, and temperature, have been recorded continuously and digitally. Electronic health records and health information technology reduce medical errors because they ensure complete information about the patient's condition. (3) However, to date, air leak information has been obtained subjectively. There is also uncertainty about the amount of fluid. Recent studies on digital drainage systems have presented an objective evaluation of these parameters, but, until now, no such studies have been conducted in children. The objective of the present study was to report our initial experience with a digital drainage system during the postoperative period of pediatric thoracic surgery.

\section{METHODS}

This was a prospective, consecutive, observational case-series study performed to evaluate the use of a digital drainage system during the postoperative period of pediatric thoracic surgery. This study is part of a project called Dreno Digital and was approved by the Research Ethics Committee of the Federal University of São Paulo/plataforma Brasil (Ruling no. 56579/2012; CAAE: 03514312.1.0000.5505).

The inclusion criteria were as follows: being treated at a pediatric thoracic surgery outpatient clinic; being $\leq$ 14 years of age; and having an indication for pulmonary resection (lobectomy or segmentectomy via muscle-sparing thoracotomy). The exclusion criteria were as follows: renal or hepatic failure; neurological dysfunction; reoperation; emergency operation; preoperative chemotherapy or radiotherapy; and chest wall resection.

The digital drainage system used was a Thopaz ${ }^{\circledR}$ device (Medela AG, Baar, Switzerland). The parameters evaluated were air leak, biosafety, duration of drainage, length of hospital stay, and complications. In children, there are no established data or parameters regarding when the chest tube can be removed; therefore, we defined an air leak flow $<10 \mathrm{~mL} / \mathrm{min}$ in the last $6 \mathrm{~h}$ as the threshold for removal.

Correspondence to:

Altair da Silva Costa Jr. Hospital São Paulo, Rua Napoleão de Barros, 715, 4ªndar, Cirurgia Torácica, Vila Clementino, CEP 04024-002, São Paulo, SP, Brasil. Tel./Fax: 5511 5576-4295. E-mail: altair.torax@gmail.com

Financial support: This study received financial support from the Fundação de Amparo à Pesquisa do Estado de São Paulo(FAPESP, São Paulo Research Foundation

Dreno Digital, Process no. 2014/24676-6). 


\section{RESULTS}

The digital drainage system was used in 11 children in this initial phase. Of those, 4 (36\%) were male and $7(64 \%)$ were female. The mean age was $5.9 \pm 3.3$ years (range, 1.6-13.0 years), with a median of 5 years. The remaining sample data are given in Table 1.

The most common clinical condition was recurrent infection, in 8 patients (72.7\%). Pulmonary malformation was the most common diagnosis, in 6 patients (54.5\%). Of those 6 patients, 2 had pulmonary sequestration and 4 had cystic adenomatoid malformation. Bronchiectasis was present in 5 patients $(45.5 \%)$. The procedures performed included pulmonary lobectomy, in 7 patients (63.6\%); segmentectomy, in 2 (18.2\%); and lobectomy plus segmentectomy, in $2(18.2 \%)$.

Only one chest tube was placed in each patient. The complication rate was $18 \%$, complications occurring in 2 of the 11 patients (atelectasis and pneumonia, respectively). There was no mortality.

Simple tracheal intubation was performed in 10 ( $91 \%)$ of the patients. Only 1 patient underwent selective intubation. All patients were extubated in the operating room, and 7 (64\%) stayed in the ICU in the immediate postoperative period.

In-hospital analgesia was provided via an epidural catheter in $8(72.7 \%)$ of the patients, all 8 of whom received a solution of $0.25 \%$ bupivacaine and fentanyl (mean, $27.7 \pm 16.9 \mathrm{~mL}$; range, 5-55 mL). The mean amount of intravenous or oral dipyrone was $8.4 \pm 4.8$ $\mathrm{g}$ (range, 2.5-18.0 g), whereas the mean amount of intravenous or oral tramadol was $118.3 \pm 154.43 \mathrm{mg}$ (range, 0-550 mg). All children underwent pulmonary resection via intercostal nerve-sparing thoracotomy using the intercostal muscle flap technique. None of the patients had rib fractures or required blood transfusion during the postoperative period. The mean intraoperative blood loss was $45.5 \pm 35.3 \mathrm{~mL}$ (range, $10-100 \mathrm{~mL}$ ). Cefuroxime was used for antibiotic prophylaxis

None of the patients had subcutaneous emphysema. Routine suction was performed until postoperative day 1 and was continued thereafter if there was no adequate lung expansion, as confirmed by chest X-ray. Only 1 patient required continuous suction until postoperative day 2. Air leak management efficiency was increased because there was no uncertainty about bubbling, regardless of the rater. Air leak flow was quantified objectively, in $\mathrm{mL} / \mathrm{min}$, the mean maximum being $92.78 \pm 95.83 \mathrm{~mL} / \mathrm{min}$ (range, $18-338 \mathrm{~mL} / \mathrm{min}$ ) and the median being $89 \mathrm{~mL} / \mathrm{min}$. All chest tubes were removed when the air leak flow was $<10 \mathrm{~mL} / \mathrm{min}$ : $0 \mathrm{~mL} / \mathrm{min}$ and $1 \mathrm{~mL} / \mathrm{min}$, respectively, in 10 patients and 1 patient. None of the patients required further drainage or had a $>4-\mathrm{cm}$ residual pleural cavity.

The information provided by the device was exported to a computer using the ThopEasy ${ }^{\circledR}$ software (Medela AG). We thus obtained more parameters, such as duration of drainage, date, start time, end time, maximum suction pressure, minimum suction pressure, maximum air leak flow, and minimum air leak flow. The data were displayed in chart and graph formats (Figure 1).

\section{DISCUSSION}

Biosafety refers to interventions focused on risk protection, prevention, and minimization for health care professionals and patients. It consists of measures adopted to prevent activity-related risks and involves the relationships among technology, risks, the human factor, and the environment. In this study, biosafety measurement was subjective, and biosafety was favorably assessed by the nursing staff because of the optimization of patient care time. The management process of the digital system was improved as compared with that of a traditional system, given that there was no need for replacing the water seal daily, caring for the bottle, clamping the system, providing continuous suction, etc.

The use of digital drainage systems in general thoracic surgery is well known. Such systems are routinely used in adults in several countries, such as Italy and Germany; however, to our knowledge, there have been no reports on their use in pediatric thoracic surgery. This might be explained by the low incidence of prolonged air leak in children. As part of the protocol developed at our institution, we studied the usefulness of such a system also in children. The traditional water-seal drainage systems used in children are the same as those used in adults and have the same limitations regarding air leak.

In a digital system, air leak flow is quantified in $\mathrm{mL} / \mathrm{min}$ and is also represented in graph format. The suction pressure is controlled by the system itself, which operates independently from the suction system of the hospital, and this provides autonomy and safety for patients and the health care team. In adults, the chest tube can be removed when the air leak flow is $>30 \mathrm{~mL} / \mathrm{min}$ in the last $6 \mathrm{~h}$, as displayed in the graph on the device screen . ${ }^{(2,4-7)}$ For children, there are no established parameters; therefore, we defined an air leak flow $<10 \mathrm{~mL} / \mathrm{min}$ in the last $6 \mathrm{~h}$ as the threshold for chest tube removal.

Table 1. Postoperative data of the patients included in the sample.

\begin{tabular}{lccc}
\multicolumn{1}{c}{ Variable } & Mean \pm SD & Minimum & Maximum \\
Length of hospital stay, days & $4.9 \pm 2.6$ & 3 & 12 \\
Duration of drainage, days & $2.5 \pm 0.7$ & 2 & 4 \\
Operative time, $\mathrm{min}$ & $166.0 \pm 42.5$ & 90 & 240 \\
Drainage volume, $\mathrm{mL}$ & $270.4 \pm 166.7$ & 135 & 750 \\
\hline
\end{tabular}



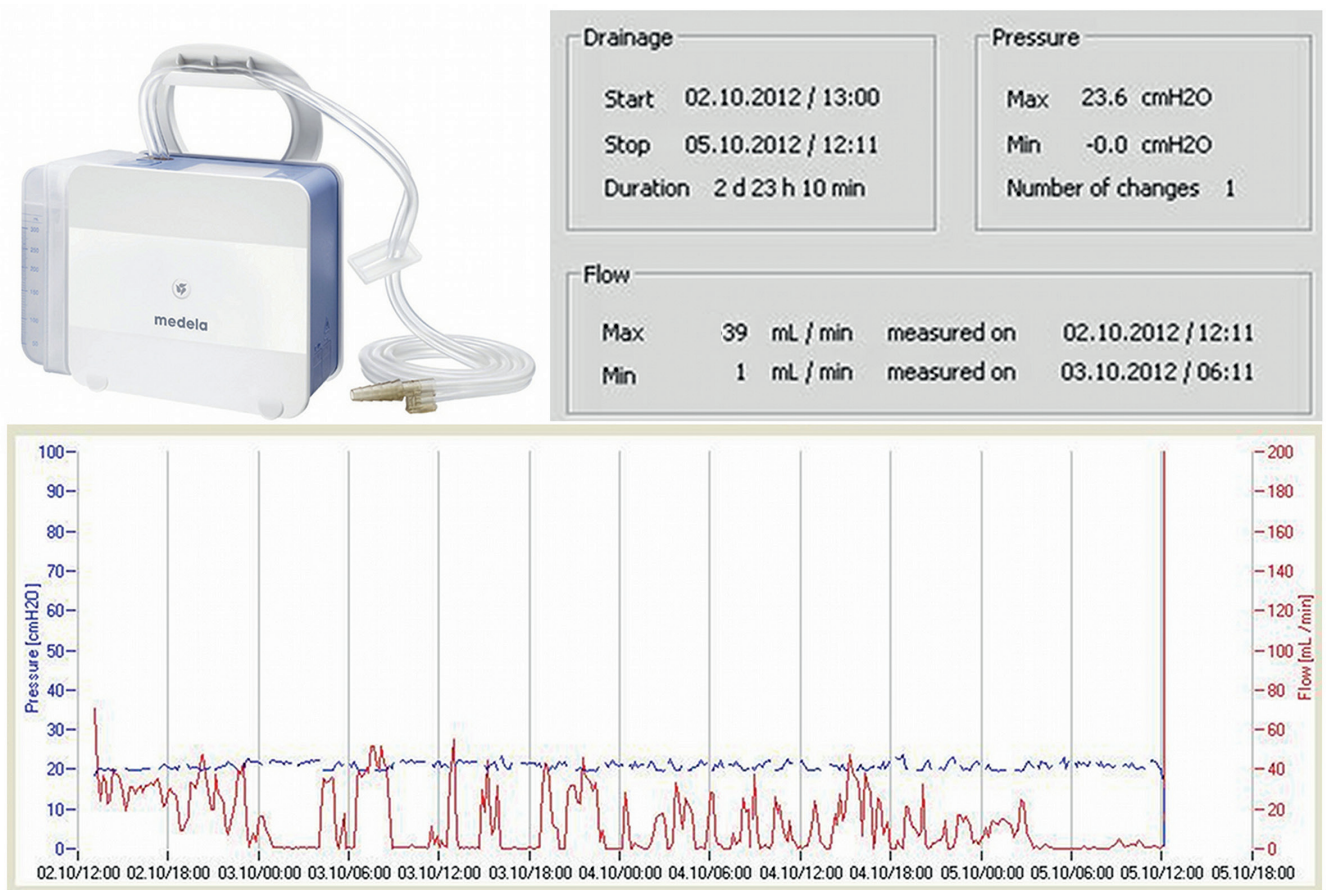

Figure 1. In the upper left, a picture of the digital device used. In the upper right and at the bottom, computer-generated data and a computer-generated graph, respectively. This information constitutes the postoperative data of an 8-year-old child who underwent a left upper lobectomy for cystic adenomatoid malformation. The duration of drainage was three days, the maximum air leak flow was $39 \mathrm{~mL} / \mathrm{min}$, and the maximum suction pressure used was $23.6 \mathrm{cmH}_{2} \mathrm{O}$. $\mathrm{Hospital}$ discharge occurred on postoperative day 4.

The system we studied was found to be functional, to be simple to use, and to offer new standards for thoracic drainage in pediatric surgery. It not only measured air leaks but also allowed early mobilization of patients, even for those on continuous suction, which is difficult to accomplish with a traditional system. ${ }^{(6,8)}$

Despite the lack of data on biosafety and thoracic drainage systems in the literature, subjective assessment by nursing staff was positive, being favored by an increase in practicality and the non-need for replacing the water seal daily. Because of minimal system handling, there is no risk of usual complications, such as lack of a water seal in the bottle, clamping of the system, chest tube disconnection or chest tube obstruction, etc. The system provided objective air leak data. Among the disadvantages is the fact that training is needed so that health care professionals can handle this new digital system and the fact that its cost is higher than that of a traditional system, mainly because of taxes and duties-the so called "custo Brasil" (cost of doing business in Brazil). To our knowledge, this is the first study on the use of this digital system in children. The digital drainage system facilitated the decision-making process during the postoperative period, thereby reducing the risk of errors in the interpretation and management of air leaks. Our study presents limited conclusions because it is a case series involving few patients. There is a need for further studies on the use of digital drainage systems in children. Such studies should include devices that already are available in other countries and measure not only air leak but also fluid flow. The use of electronic health records is inevitable.

\section{REFERENCES}

1. Costa Jr Ada S, Leão LE, Succi JE, Rymkiewicz E, Folador J, Kazantzis T. Digital drainage system: how far can we go? J Bras Pneumol. 2014;40(5):579-81. https://doi.org/10.1590/S180637132014000500015

2. Cerfolio RJ, Bryant AS. The benefits of continuous and digital air leak assessment after elective pulmonary resection: a prospective study. Ann Thorac Surg. 2008;86(2):396-401. https://doi.org/10.1016/j athoracsur.2008.04.016

3. Ajami S, Bagheri-Tadi T. Barriers for Adopting Electronic Health Records (EHRs) by Physicians. Acta Inform Med. 2013;21(2):129-34. https://doi.org/10.5455/aim.2013.21.129-134

4. Mier JM, Molins L, Fibla JJ. The benefits of digital air leak assessment after pulmonary resection: prospective and comparative study [Article in Spanish]. Cir Esp. 2010,87(6):385-9. https://doi. org/10.1016/j.ciresp.2010.03.012

5. Cerfolio RJ, Varela G, Brunelli A. Digital and smart chest drainage systems to monitor air leaks: the birth of a new era? Thorac Surg Clin 2010;20(3):413-20. https://doi.org/10.1016/j.thorsurg.2010.03.007

6. Bertolaccini L, Rizzardi G, Filice MJ, Terzi A. "Six Sigma approach" - an objective strategy in digital assessment of postoperative air leaks: a prospective randomized study. Eur J Cardiothorac Surg. 2011;39(5):e128-32. https://doi.org/10.1016/j.ejcts.2010.12.027

7. Pompili C, Detterbeck F, Papagiannopoulos K, Sihoe A, Vachlas K Maxfield MW, et al. Multicenter international randomized comparison of objective and subjective outcomes between electronic and traditional chest drainage systems. Ann Thorac Surg. 2014;98(2):4906; discussion 496-7. https://doi.org/10.1016/j.athoracsur.2014.03.043

8. Pompili C, Brunelli A, Salati M, Refai M, Sabbatini A. Impact of the learning curve in the use of a novel electronic chest drainage system after pulmonary lobectomy: a case-matched analysis on the duration of chest tube usage. Interact Cardiovasc Thorac Surg. 2011;13(5):4903; discussion 493. https://doi.org/10.1510/icvts.2011.280941 